\title{
COMPONENTES ATIVOS DE ORIGEM ANIMAL
}

\author{
CLAUDIO LIMA AGUIAR* \\ FABIO AUGUSTO GARCIA CORÓ** \\ MAYKA REGHIANY PEDRÃO**
}

\begin{abstract}
A presente revisão teve como objetivo discutir as atividades fisiológicas relacionadas aos componentes de origem animal. Foram abordados o leite e seus componentes, os produtos cárneos, os componentes de sangue bovino e a regulamentação dos alimentos funcionais ou nutracêuticos. Conclui-se que apesar de bastante estudadas os componentes ativos de origem animal ainda não são integralmente compreendidos. Como fonte de alimentos e ingredientes alimentares, esses componentes podem ser empregados para solucionar ou minimizar deficiências nutricionais. No entanto, a necessidade e importância do estudo de compostos bioativos têm sido associadas à demanda cada vez maior desses tipos de ingredientes pelo mercado consumidor.
\end{abstract}

PALAVRAS-CHAVE: ORIGEM ANIMAL; NUTRACÊUTICOS; PROPRIEDADES FISIOLÓGICAS.

\section{INTRODUÇÃO}

Os compostos químicos obtidos de fontes naturais são importantes na formulação de novas drogas. Isto é claramente ilustrado pelo fato de muitos antibióticos e antitumorais serem extraídos de diferentes plantas conhecidas pela medicina folclórica (CRAGG, NEWMAN e SNADER, 1997). A atividade biológica dessas plantas tem sido facilmente observada pela utilização de culturas celulares in vitro. De todas as drogas aprovadas entre 1983 e 1994, 78\% dos novos antibióticos e 61\% dos novos antitumorais foram obtidos de fontes naturais ou de derivados de produtos naturais. Diferentes motivos podem explicar o crescimento dos estudos sobre produtos naturais, como a pesquisa para desenvolvimento de novas

* Professor, Doutor em Ciência de Alimentos, Centro de Pesquisa em Ciência e Tecnologia do Leite, Universidade Norte do Paraná, Tamarana, PR, Brasil (email: claguiar@yahoo.com.br).

** Professor, Doutor em Ciência de Alimentos, Curso de Engenharia de Alimentos, Universidade Norte do Paraná, Londrina, PR, Brasil. 
drogas, a importância da biotecnologia para a indústria farmacêutica, a validação de medicamentos utilizados pela medicina tradicional e o crescente interesse pela fitoterapia. Todos esses fatos estão associados com a riqueza da flora brasileira, a qual representa mais de $20 \%$ das espécies de plantas do mundo (PETROVICK, MARQUES e PAULA, 1999).

Os alimentos são produtos agrícolas, comerciais ou produtos essenciais para a saúde pública (FERNICOLA, 2001). Os alimentos que promovem benefícios à saúde, além da função nutritiva, ou apresentam papel na prevenção ao risco de doenças são denominados alimentos funcionais. Esses podem prevenir ou contribuir para o tratamento de doenças cardiovasculares, câncer, osteoporose e desordens imunológicas (PENNINGTON, 2002). O câncer é a segunda principal causa de mortes nos Estados Unidos, superada apenas pelas doenças cardiovasculares. Entretanto, sabe-se que de 30 e $40 \%$ de novos casos de câncer poderiam ser evitados pela adoção de dietas apropriadas e desenvolvimento de atividade física para manutenção de peso corporal adequado (OHR, 2002).

Os ingredientes benéficos dos alimentos funcionais têm sido denominados de componentes funcionais e de componentes bioativos. Tais ingredientes exercem acões antioxidantes, ativando enzimas hepáticas contra intoxicações, bloqueando toxinas bacterianas ou virais, inibindo a absorção de colesterol, diminuindo a agregação de plaquetas ou inibindo bactérias gastrointestinais indesejáveis. Componentes bioativos incluem grande número de compostos químicos com estruturas variadas, dentre os quais carotenóides, flavonóides, esteróis, ácidos graxos poliinsaturados e ácidos fenólicos (PENNINGTON, 2002). Contudo componentes bioativos encontrados em produtos de origem animal também são descritos (Quadro 1).

\section{QUADRO 1 - COMPONENTES BIOATIVOS ENCONTRADOS EM PRODUTOS DE ORIGEM ANIMAL}

\begin{tabular}{|l|l|}
\hline Produtos animais & Componentes ativos \\
\hline Produtos lácteos & Ömega-3 (ácido linolênico) \\
\hline Peixes* & Ômega-3 (ácido alfa-linoléico conjugado) \\
\hline Carnes & Ômega-3 (ácido linolênico conjugado) \\
\hline logurte/Leites fermentados & Culturas bacterianas (probióticos) \\
\hline
\end{tabular}

*Especialmente, peixes de água fria, salmão, sardinhas, cavala, espadarte e tilapia. Adaptado de PENNINGTON (2002). 
Tem sido evidenciado que vários componentes bioativos, amplamente difundidos nos alimentos de origem animal, apresentam atividade fisiológica (PRATES e MATEUS, 2002). Assim, a presente revisão teve como objetivo discutir algumas atividades fisiológicas relacionadas aos componentes ativos de origem animal.

\section{REGULAMENTAÇÃO DOS ALIMENTOS FUNCIONAIS OU NUTRACÊUTICOS}

O termo alimentos funcionais apareceu pela primeira vez no Japão, na década de 80, para designar alimentos cujos ingredientes ativam funções corporais determinadas além do seu papel nutritivo. O Japão é o único país que conta com regulamento específico para aprovação de alimentos funcionais (ARAI, 1996).

Tem sido crescente o interesse dos consumidores pelo efeito benéfico para a saúde de determinados alimentos, ou de componentes com atividades fisiológicas (HASLER, 1998). Sob o ponto de vista mercadológico, o consumo de alimentos funcionais tem aumentado e as indústrias têm colocado à disposição dos consumidores número cada vez maior desses produtos. Em matéria divulgada no Nutrition Business Journal, o valor do mercado americano para alimentos funcionais foi estimado em US\$19,6 bilhões para 1999 e em US\$ 20 bilhões para 2000. Isso constituiria $10 \%$ do mercado total de alimentos para 2010 , quando poderá atingir cerca de US\$ 60 bilhões de acordo com as projeções da revista (HENRY, 1999). O crescente interesse por esse tipo de alimento pode ser explicado pelo grande número de mortes associadas com a alimentação. Levantamento efetuado em 1997, nos Estados Unidos sobre as causas de mortes revelou a seguinte distribuição: $31 \%$ por doenças coronarianas, 23\% por câncer, 7\% por doenças cerebrovasculares e $5 \%$ por doenças obstrutivas do pulmão (WEISBURGER, 2000). As cardiopatias constituem uma das principais causas de morte em todo o mundo, seguidas pelos vários tipos de câncer. Felizmente, muitos estudos têm mostrado a capacidade de prevenção dessas doenças pela adoção de dieta adequada (MORAIS, 2001; MARANHÃO, 2001).

Muitas organizações propuseram definições para os alimentos funcionais. A legislação americana considera esses alimentos como suplemento dietético, ou alimento medicinal que apresenta benefícios à saúde e é seguro para o consumo humano em quantidade e freqüência requeridas 
para se alcançar as propriedades sugeridas (HENRY, 1999; IFIC, 1998; CLYDESDALE, 1997). O Institute of Medicine of the National Academy of Sciences (IMNAS) define alimentos funcionais como aqueles cujas concentrações de um ou mais ingredientes foi manipulada ou modificada de modo a incrementar sua contribuição para a dieta saudável (IMNAS, 1994).

No Brasil, a regulamentação técnica dos alimentos ditos "funcionais" foi proposta e aprovada em 1998 pela Agência Nacional de Vigilância Sanitária. Foram estabelecidos os seguintes regulamentos: Resolução ANVS/MS no16 (Regulamento Técnico de Procedimentos para Registro de Alimentos e/ou Novos Ingredientes), Resolução ANVS/MS nำ17 (Regulamento Técnico que estabelece as Diretrizes Básicas para Avaliação de Risco e Segurança dos Alimentos), Resolução ANVS/MS no18 (Regulamento Técnico que estabelece as Diretrizes Básicas para Análise e Comprovação de Propriedades Funcionais e/ou de Saúde alegadas em Rotulagem de Alimentos) e Resolução ANVS/MS №19 (Regulamento Técnico de Procedimentos para Registro de Alimentos com Alegação de Propriedades Funcionais e/ou de Saúde em sua Rotulagem) (ANVISA, 2004a).

Constantes aperfeiçoamentos da legislação sanitária brasileira têm sido necessários visto ao grande interesse pelos alimentos com ingredientes fisiologicamente ativos. As Diretrizes Básicas para Análise e Comprovação de Propriedades Funcionais e/ou de Saúde Alegadas em Rotulagem de Alimentos (Resolução n18, de 30 de abril de 1999, republicada em 3 de dezembro de 1999) têm buscado soluções para o uso de alimentos com alegações benéficas à saúde, ou ainda, sobre as necessidades de pessoas em condições fisiológicas especiais, efeitos benéficos de outros compostos não-nutrientes, e fatores ligados à urbanização (como o aumento da expectativa de vida) os quais vêm estimulando a produção de alimentos funcionais (ANVISA, 2004b).

É importante notar que as alegações podem fazer referências à manutenção geral da saúde, ao papel fisiológico dos nutrientes e nãonutrientes e à redução de risco a doenças, não sendo permitidas alegações com relação à cura ou prevenção de doenças. A ANVISA (2004b) define como propriedade de saúde àquela que afirma, sugere ou implica na existência de relação entre o alimento ou ingrediente com doença ou condição relacionada à saúde, sendo essas alegações de caráter opcional ao produtor durante a rotulagem do produto. 
Deve-se ressaltar que o uso generalizado e a aceitação do termo alimentos funcionais por cientistas, comunicadores e consumidores, torna conveniente mantê-lo. Sua substituição por terminologia cientificamente mais apropriada poderia aumentar ainda mais a confusão dos consumidores (ADA, 1999).

\section{LEITE E SEUS COMPONENTES}

O leite, secreção fluida das fêmeas de todas as espécies de mamíferos, é produzido por mais de quatro mil espécies de mamíferos com a função de suprir necessidades nutricionais de neonatos. Esse fluido exerce também várias funções fisiológicas por meio de suas proteínas e peptídeos, tais como imunoglobulinas, enzimas, inibidores enzimáticos, fatores de crescimento e agentes antimicrobianos (ANTUNES, 2003). Os componentes ativos do leite (Tabela 1) variam de acordo com a estação do ano e diferenças entre raças, estágio de lactação e o sistema de alimentação dos mamíferos (ANTUNES, 2003; CUNNINGHAM, 1999).

\section{TABELA 1 - PRINCIPAIS COMPONENTES DO LEITE DE DIFERENTES ESPÉCIES DE MAMÍFEROS (VALORES MÉDIOS)}

\begin{tabular}{lcccc}
\hline Espécies & Gordura(\%) & Proteína(\%) & Lactose(\%) & Cinzas(\%) \\
\hline Gata & 7,1 & 10,1 & 4,2 & 0,5 \\
Vaca da raça Hblstein & 3,5 & 3,1 & 4,9 & 0,7 \\
Cadela & 9,5 & 9,3 & 3,1 & 1,2 \\
Cabora & 3,5 & 3,1 & 4,6 & 0,8 \\
Égua & 1,6 & 2,4 & 6,1 & 0,5 \\
\hline
\end{tabular}

Fonte: Adaptado de CUNNINGHAM (1999).

\subsection{COLOSTRO}

Segundo CUNNINGHAM (1999), a secreção de leite antes do parto (sem remoção) resulta no colostro. Sua formação representa processo secretório no qual a lactogênese acontece na ausência da remoção do leite. A lactação, no entanto, não pode ocorrer até que a gestação chegue ao seu final. Isto se deve aos efeitos inibidores da progesterona e de estrogênios sobre a secreção do leite, fatores que são removidos no momento do parto ou pouco antes dele. 
Mamíferos jovens apresentam trato gastrointestinal pouco desenvolvido para distribuir adequadamente os biomateriais estranhos e os componentes do leite aceleram o desenvolvimento de muitas das funções vitais do intestino (GIBSON, 1998). O colostro participa da maturação da superfície do intestino e do sistema imune (BESSI, 2001; GOLDMAN, 2000). O colostro ainda exerce importante função na proteção passiva contra agentes infecciosos. As imunoglobulinas, principalmente a imunoglobulina $A(\lg A)$, são produzidas na glândula mamária pelos plasmócitos como resultado da exposição do organismo materno a certos microrganismos, tendo acesso ao leite pela migração dos plasmócitos de tecidos de locais adjacentes. As imunoglobulinas estão altamente concentradas no colostro e pelo seu consumo os neonatos podem receber imunidade passiva contra experiências patogênicas vividas pela mãe. $O$ colostro constitui rica fonte de vitamina A, caseínas, albuminas e lipídios (CUNNINGHAM, 1999). A Tabela 2 apresenta as quantidades de componentes presentes no colostro bovino em função da porcentagem dos níveis em leite bovino normal.

\section{TABELA 2 - COMPONENTES PRESENTES NO COLOSTRO BOVINO EM FUNÇÃO DA PORCENTAGEM DOS NÍVEIS EM LEITE BOVINO NORMAL}

\begin{tabular}{lccc}
\hline \multirow{2}{*}{ Componente } & \multicolumn{3}{c}{ Dias pós-parto } \\
\cline { 2 - 4 } & 0 & 3 & 5 \\
\hline Matéria seca & 220 & 100 & 100 \\
Lactose & 45 & 90 & 100 \\
Lipídios & 150 & 90 & 100 \\
Minerais & 120 & 100 & 100 \\
Proteínas & & & \\
$\quad$ Caseína & 210 & 110 & 110 \\
$\quad$ Albumina & 500 & 120 & 105 \\
$\quad$ Globulina & 3500 & 300 & 200 \\
Vitaminas & & & \\
A & 600 & 120 & 100 \\
Caroteno & 1200 & 250 & 125 \\
E & 500 & 200 & 125 \\
$\quad$ Tiamina & 150 & 150 & 150 \\
Riboflavina & 320 & 130 & 110 \\
$\quad$ Ácido pantotênico & 45 & 110 & 105 \\
\hline
\end{tabular}

Fonte: Adaptado de CUNNINGHAM (1999). 


\subsection{PROTEÍNAS DO LEITE}

O leite contém grande variedade de componentes protéicos (Tabela 3) que tipicamente podem ser divididos em duas classes, distinguidas pelas suas solubilidades no leite não-aquecido a pH 4,6 e 20ㄷ: as caseínas (insolúveis) e as proteínas do soro (solúveis) (AIMUTIS, 2004).

\section{TABELA 3 - PORCENTAGENS MÉDIAS DAS PROTEÍNAS PRESENTES NO LEITE BOVINO*}

\begin{tabular}{lccc}
\hline Componentes & Total & Caseína & Soro \\
\hline Caseínas & 80 & & \\
caseína $\alpha_{\mathrm{s} 1}$ & 36 & 45 & \\
caseína $\alpha_{\mathrm{s} 2}$ & 9 & 11 & \\
$\beta$-caseína & 21 & 26 & \\
א-caseína & 12 & 15 & \\
$\gamma$-caseína & 4 & 5 & 50 \\
Soro & 20 & & 20 \\
$\beta$-lactoglobulina & 10 & & 10 \\
$\alpha$-lactalbumina & 4 & & 5 \\
Imunoglobulinas & 2 & & $1-2$ \\
Albumina do soro & 1 & & 0,5 \\
Lactoferrina & & & 0,1 \\
Lactoperoxidase & & & \\
Lisozima & & & \\
\hline
\end{tabular}

* Valores expressos em porcentagem presente nas frações.

Fonte: Adaptado de ANTUNES (2003).

Apesar das caseínas constituírem aproximadamente $80 \%$ das proteínas do leite bovino, seu soro contém várias proteínas (principalmente $\alpha$ lactalbumina e beta-lactoglobulina), peptídeos, aminoácidos, lactose, minerais, vitaminas e quantidades variáveis de lipídios (MEISEL e BOCKELMANN, 1999). O precipitado ácido de caseína contém todas as proteínas da caseína, mas quando formado pela ação da quimosina, essa ataca especificamente a $\kappa$-caseína sobre a superfície micelar da caseína (FARREL et al., 1999) e origina constituinte denominado caseinoglicomacropeptídeo (CGMP). Trata-se de polipeptídeo com 64 resíduos de aminoácidos derivados do terminal-C da א-caseína bovina (YVON et al., 1994; BAL-DIT-SOLLIER et al., 1996) e sua presença no soro de leite tem significativa influência nas propriedades biológicas desse co-produto (WALZEM, DILLARD e GERMAN, 2002). Caseínas ocorrem basicamente na forma de micelas estabilizadas pelo fosfato de cálcio. 
Constituem família heterogênea de proteínas predenominadas como: $\alpha_{\mathrm{s} 1}{ }^{-}, \alpha_{\mathrm{s} 2}{ }^{-}, \beta$ - e $\kappa$-caseínas (EIGEL et al., 1984).

Muitos dos componentes fisiologicamente ativos são constituintes com menor presença no leite (Quadro 2).

\section{QUADRO 2 - PROTEÍNAS FISIOLOGICAMENTE ATIVAS SECRETADAS NO LEITE BOVINO}

\begin{tabular}{|c|c|}
\hline Proteínas protetoras & Hormônios \\
\hline Imunoglobulinas & \multirow{8}{*}{$\begin{array}{l}\text { Hormônio de liberação de tirotropina (TRH) } \\
\text { Somatostatina (SIH) } \\
\text { Calcitonina } \\
\text { Insulina } \\
\text { Relaxina } \\
\text { Hormônio estimulante da tiróide (TSH) } \\
\text { Hormônio de liberação luteinizante (LRH) } \\
\text { Peptídeo de liberação de gastrina (GRP) } \\
\text { Adrenocorticotropicormona (ACTH) } \\
\text { Prolactina }\end{array}$} \\
\hline Proteose peptonas & \\
\hline Lactoferrina & \\
\hline Transferina & \\
\hline Fatores de crescimento & \\
\hline $\begin{array}{l}\text { Fator de crescimento epidermal (EGF) } \\
\text { Fator beta de crescimento de tecidos (TGF } \beta \text { ) } \\
\text { Fator de crescimento ligado à insulina (IGF-1) }\end{array}$ & \\
\hline Enzimas & \\
\hline $\begin{array}{l}\text { Lactoperoxidase } \\
\text { Lisozima } \\
\text { Plasmina } \\
\text { Xantina oxidase } \\
\text { Glicose oxidase }\end{array}$ & \\
\hline
\end{tabular}

Fonte: Adaptado de AIMUTIS (2002)

Segundo POTTER et al. (1993) dieta rica em proteínas vegetais constitui fator importante no conteúdo de lipídios do soro sanguíneo. De acordo com CARROL (1991) e CARROL e KUROWSKA (1995) as proteínas de origem animal (como caseínas) são geralmente hipercolesterolêmicas e aterogênicas, quando comparadas com as proteínas vegetais conforme experimentos com animais e humanos. No entanto, SAUTIER et al. (1983) e NAGAOKA et al. (1992) reportaram que proteínas do soro de leite apresentam efeito hipolipidêmico comparável ao de caseínas e proteínas da soja.

\subsection{CÁLCIO}

O leite de vaca contém aproximadamente 1,20 g de cálcio por litro, 20\% dos quais ligados à caseína como colóide orgânico insolúvel e 80\% na forma de mineral (COBAYASHI, 2004). O cálcio nos queijos está prontamente disponível, mesmo contendo grandes quantidades de ácidos 
graxos de cadeia longa e pouca lactose. Nas situações desfavoráveis, como nos casos de pH elevado, o cálcio do leite mantém-se em suspensão devido a sua ligação aos peptídeos e proteínas. O leite não contém nenhuma substância para inibir a absorção de cálcio no intestino como, oxalatos, fitatos ou polifenóis (GUÉGUEN e POINTILLART, 2000).

O consumo adequado de cálcio durante a vida constitui pré-requisito para a saúde dos ossos. O cálcio é necessário para o desenvolvimento ósseo durante o crescimento e para a manutenção da integridade do esqueleto durante toda a vida adulta. Um dos mais importantes determinantes do risco de osteoporose pós-menopausa é a quantidade de massa esquelética adquirida durante a infância e adolescência. A deficiência de cálcio pode acarretar, além da perda da massa óssea, problemas como cãibras e irritabilidade por tratar-se de mineral necessário para a transmissão nervosa e regulação dos batimentos cardíacos (KRAUSE e MAHAN, 1991). Estudos indicam que o cálcio originado do leite e seus derivados exercem efeitos atribuídos aos constituintes bioativos presentes em sua constituição, que agem sinergicamente com o cálcio na atenuação de sua disponibilidade (ZEMEL e MILLER, 2004).

Os lipídios dietéticos, particularmente triglicérides e ácidos graxos saturados com baixo peso molecular, formam "sabões" insolúveis com o cálcio dietético, aumentando sua excreção fecal e, conseqüentemente, reduzindo sua absorção. Durante a administração de produtos lácteos em mulheres, apresentando osteopenia e osteoporose, verificou-se que a opção pelo leite desnatado favorece a absorção do cálcio em virtude da não-formação de "sabões" insolúveis com o cálcio dietético (COELHO, 1995).

Lactose, caseinato e citrato são componentes presentes no leite que mantém a solubilidade do cálcio no lúmen intestinal, uma vez que o cálcio é pouco solúvel em água. A lactose, dissacarídeo formado por glicose e galactose, sofre a ação da enzima $\beta$-galactosidase no enterócito, desdobrando-se nesses monossacarídeos e liberando o cálcio. A manutenção dessa solubilidade parece favorecer a melhor absorção do cálcio em relação a outros alimentos que contêm cálcio (GRUDTNER, WEINGRILL e FERNANDES, 1997).

\subsection{SORO DE LEITE BOVINO}

Tradicionalmente, o soro de leite bovino é definido como subproduto da indústria queijeira com pouco ou nenhum valor econômico. Essa visão 
está mudando radicalmente com suas novas aplicações tecnológicas ou nutricionais, tornando-o co-produto da indústria queijeira (WALZEM, DILLARD e GERMAN, 2002). As proteínas do soro de leite (20\% do total de proteínas), assim como as caseínas constituem família heterogênea de grupo polimórfico de proteínas distribuídas em: $\alpha$-lactalbumina $(\alpha-L A$, $20 \%$ ), $\beta$-lactoglobulina ( $\beta$-Lg, $50 \%$ ), albumina do soro (BSA, 10\%), imunoglobulinas (10\%) e proteose peptonas (<10\%) (AIMUTIS, 2004).

As atividades regulatórias exercidas por seqüências bioativas derivadas do leite incluem: modulação das funções digestivas, gastrointestinais e hemodinâmicas (hipertensão e fluxo gástrico do sangue), anticariogenicidade, propriedades analgésicas, fatores de crescimento, imunorregulação e defesa contra doenças não-imunes. Muitas bioatividades são expressas pelos peptídeos derivados da seqüência de aminoácidos das proteínas nativas do leite. Proteases digestivas, ou proteólise in vitro, liberam peptídeos ativos que podem apresentar atividades biológicas benéficas ao ser humano (AIMUTIS, 2002; SHAH, 2000; STEIJNS, 2001).

A molécula da beta-lactoglobulina ( $\beta-\mathrm{Lg})$, proteína presente em maior quantidade no soro de leite bovino, contém 162 resíduos de aminoácidos com massa molecular total de aproximadamente $18 \mathrm{kDa}$, organizada em $15 \%$ da estrutura protéica como alfa-hélice, $43 \%$ de beta-pregueada e $47 \%$ de estrutura não-organizada (ANTUNES, 2003). Está presente no leite de todos os ruminantes e ausente no leite de quase todos os nãoruminantes. Embora tenha sido isolada há mais de 60 anos e várias atividades biológicas tenham sido atribuídas a essa proteína, sua função ainda é desconhecida (ANTUNES, 2003; WALZEM, DILLARD e GERMAN, 2002). Considerando que a estrutura secundária da $\beta$-Lg seja homóloga às das proteínas ligadoras de retinol, a $\beta$-Lg pode estar associada com a ligação de vitamina $A$ nas glândulas mamárias (ANTUNES, 2003; SAID, ONG e SHINGLETON, 1989). A $\beta$-Lg (ligadora de retinol, apolipoproteína $D$, globulina $\alpha$-2-urinária e de bilina) exerce função de ligação ou transporte de moléculas hidrofóbicas pequenas (ALI e CLARK, 1988), embora essa função ainda não seja verdadeiramente reconhecida. No entanto, a $\beta$-Lg pode ter a função de proteína ligadora de lipídios ou ácidos graxos (PEREZ e CALVO, 1995).

A $\alpha$-lactalbumina constitui $2 \%$ das proteínas totais do leite e $13 \%$ das do soro. É a única proteína do soro capaz de se ligar ao cálcio e seu alto teor de triptofano apresenta benefícios na regulação do sono e melhora do humor (ANTUNES, 2003). Sendo proteína ligada ao cálcio pode ainda 
ter grande afinidade por outros metais como zinco, manganês, cádmio, cobre e alumínio (WALZEM, DILLARD e GERMAN, 2002). Trata-se de proteína ligada ao complexo lactose-sintetase que catalisa o último passo na biossíntese da lactose, sendo importante na secreção de leite (TAWA e GOLDBERG, 1992). A lactose, principal carboidrato da maioria dos mamíferos, é composta por glicose e galactose. O açúcar sanguíneo é o principal precursor da molécula de lactose e o propionato importante precursor da glicose nos ruminantes. A lactose é formada sob o comando da lactose-sintetase, enzima composta de $\alpha$-lactalbumina e galactosiltransferase. A síntese da lactose é inibida até momentos antes do parto, porque a progesterona impede a formação de $\alpha$-lactalbumina. Já a prolactina estimula a produção de lactose-sintetase (CUNNINGHAM, 1999). A $\alpha$-lactalbumina produz aminoácidos de cadeia ramificada utilizados pelos músculos como fonte energética e na síntese de proteínas, estando associados ao aumento da eficiência muscular (BLOMSTRAND e NEWSHOLME, 1992; SCHENA et al., 1992).

A albumina do soro bovino (BSA), proteína globular de grandes dimensões (69 kDa), é composta por cerca de 582 resíduos de aminoácidos (particularmente, aminoácidos essenciais) com dezessete ligações dissulfídicas intramoleculares e um grupo tiol livre no resíduo 34. Tratase de proteína transportadora de ácidos graxos insolúveis no sistema circulatório, podendo se ligar a outros lipídios e substâncias responsáveis por certas características sensoriais (ANTUNES, 2003).

Quatro das cinco imunoglobulinas (lgA, $\lg \mathrm{E}, \lg \mathrm{G}$ e $\lg \mathrm{M}$ ) ocorrem em baixas concentrações no leite bovino (ANTUNES, 2003). CUNNINGHAN (1999) relata que suas concentrações são maiores no colostro e que os neonatos podem receber proteção imediata contra organismos ambientais e anticorpos pela ingestão do colostro. A IgG, principal imunoglobulina presente no leite bovino, representa $80 \%$ do total das imunoglobulinas. As cadeias polipeptídicas das imunoglobulinas contêm regiões de aminoácidos constantes e variáveis, responsáveis por várias funções como transporte em membranas e ligação de antígenos, sendo a principal função da IgG no leite promover imunidade passiva aos neonatos (ANTUNES, 2003). AIMUTIS (2004) relatou que as imunoglobulinas apresentam atividade protetiva mesmo em experimentos in vitro. As imunoglobulinas ainda podem contribuir na proteção contra agentes causadores da diarréia, segundo estudos de CRAVIOTTO et al. (1991) e CRUZ et al. (1988).

Compreendendo pequena porção $(0,2-0,8 \%)$ das proteínas do leite, a 
lactoferrina (Lf) apresenta grande concentração no soro de leite e foi isolada do componente-3 dos peptídeos derivados da caseína (fragmentos de beta-caseína) (ANTUNES, 2003; SEYFERT et al., 1994). Trata-se de proteína ligadora de ferro, com massa molecular da ordem de 76 kDa. Polimeriza-se rapidamente com cálcio e apresenta atividade antimicrobiana pelo seqüestro de ferro do meio (ANTUNES, 2003; WALZEM, DILLARD e GERMAN, 2002; ARAÚJO e GIUGLIANO, 2001). Segundo GIUGLIANO et al. (1995) essa glicoproteína ligadora de ferro está envolvida na inibição da aderência de Escherichia coli enterotoxigênica. A Lf seqüestra e solubiliza ferro, controlando a sua quantidade disponível no metabolismo intestinal. Isolada há cerca de 30 anos, as funções biológicas da Lf são ainda emergentes (GOODMAN e SCHANBACHER, 1991). Em geral, as propriedades biológicas da Lf incluem atividades antibacterianas e antivirais, prevenção do crescimento de organismos patogênicos no intestino, estímulo do sistema imune, regulação do metabolismo de ferro e controle dos danos causados em células e tecidos (AL-MASHIKHI e NAKAI, 1987).

\subsection{LIPÍDIOS DO LEITE}

Doenças cardíacas, câncer de cólon e outras enfermidades eram atribuídas há alguns anos aos ácidos graxos do leite. No entanto, diversos trabalhos têm revelado importantes funções de alguns lipídios (SANDERS, 1998). O ácido linoléico atua na inibição do câncer e de aterosclerose, na melhoria das funções imunológicas, nos efeitos de atração do ácido butírico para a eliminação de células cancerosas do cólon, e na função regulatória celular dos fosfolipídios da membrana plasmática (JELEN e LUTZ, 1998).

Embora a concentração de lipídios no soro de leite seja baixa, a quantidade presente nas suas preparações comerciais depende das técnicas de fracionamento (WALZEM, DILLARD e GERMAN, 2002). Para VAGHELA e KILARA (1996) e VESPER et al. (1999), a maior classe de lipídios presente no soro de leite é a dos triacilgliceróis, seguido pelos fosfolipídios (esfingomielina, fosfatidil-colina, fosfatidil-etanolamina, fosfatidil-inositol, fosfatidil-serina e cerebrosídeos), diacilgliceróis, ácidos graxos livres (ácido butírico, ácido oléico, ácido capróico e ácido caprílico), ésteres de colesterol, colesterol e monoacilgliceróis (C-8:0 (sn-1); C-10:0 (sn-1); C-12:0 (sn-1); C-14:0 (sn-1); C-16:0 (sn-1); C-18:0 (sn-1); C-18:1 (sn-1); C-18:0 (sn-2); e C-16:0 (sn-2)). Algumas funções atribuídas a esses componentes são listadas no Quadro 3. 


\section{QUADRO 3 - COMPONENTES FISIOLOGICAMENTE ATIVOS DERIVADOS DE LIPÍDIOS DO LEITE}

\begin{tabular}{|c|c|}
\hline Componentes & Função atribuída \\
\hline Ácido $\gamma$-amino-butírico & Antihipertensivo \\
\hline Ácido butírico & Eliminação de células cancerosas do cólon \\
\hline Ácidos graxos ômega-3 & $\begin{array}{l}\text { Previnem enfermidades coronarianas e ataques } \\
\text { cardíacos } \\
\text { Desenvolvimento da retina e do cérebro } \\
\text { Prevenção de disfunções autoimunes } \\
\text { Prevenção da doença de Crohn } \\
\text { Prevenção do câncer de mama, cólon e próstata } \\
\text { Regulação da hipertensão } \\
\text { Prevenção de artrite reumatóide }\end{array}$ \\
\hline Ácido linolêico conjugado & $\begin{array}{l}\text { Inibição de câncer } \\
\text { Inibição de aterosclerose } \\
\text { Melhoramento do sistema imunológico } \\
\text { Antimutagênico }\end{array}$ \\
\hline Esfingolipídios da membrana & $\begin{array}{l}\text { Regulação do comportamento celular } \\
\text { Controle do câncer de cólon } \\
\text { Redução das lipoproteínas de baixa densidade } \\
\text { Aumento das lipoproteínas de alta densidade }\end{array}$ \\
\hline $\begin{array}{l}\text { Produtos metabólicos de triglicerídeos e } \\
\text { fosfolipídios }\end{array}$ & Atividades antimicrobianas e antivirais \\
\hline Ácidos graxos de cadeia curta e Fosfolipídios & $\begin{array}{l}\text { Prevenção contra enteropatógenos } \\
\text { Efeito protetor contra úlceras gástricas } \\
\text { Defesa contra Listeria }\end{array}$ \\
\hline
\end{tabular}

Fonte: Adaptado de HERNANDEZ e GUZMAN (2003).

\section{PRODUTOS CÁRNEOS}

Os alimentos de origem animal apresentam elevado valor nutricional quando comparado aos de origem vegetal. Todavia não é correto afirmar que a alimentação depende de carnes e derivados, pois existem fontes alternativas de proteínas e aminoácidos. No entanto, tal substituição exige conhecimento sobre nutrição e fisiologia humana (LEMOS, 2003).

Além das proteínas, a carne constitui excelente fonte de ferro, zinco e vitaminas do complexo B (WARD e GERMAN, 2003). A participação do zinco no sistema de proteção antioxidante foi evidenciada por meio de estudos in vivo e in vitro. Os primeiros demonstram que a deficiência de zinco provoca lesões oxidativas relacionadas à ação de espécies reativas 
de oxigênio em animais e em humanos. Já os estudos in vitro demonstram o antagonismo do zinco à formação de radicais livres em modelos bioquímicos e celulares (KOURY e DONANGELO, 2003).

A indústria de carnes tem se preocupado com os lipídios presentes nesse tipo de alimento, pois estão relacionados com as gorduras saturadas, as doenças de coração e o colesterol (MORRISSEY, 1998). A oxidação lipídica em alimentos é considerada como fator de risco para a saúde humana, pois os produtos formados (óxidos de colesterol, em particular) podem ser carcinogênicos, mutagênicos e teratogênicos (CHIZZOLINI, NOVELLI e ZANARDI, 1998).

Em geral, as quantidades de lipídios naturalmente estocados nos músculos dependem principalmente das condições alimentares do animal, sua digestão, absorção intestinal, metabolismo hepático e transporte de lipídios para a musculatura (GEAY et al., 2001). Em ruminantes, elevada proporção dos ácidos graxos insaturados provenientes da dieta são hidrogenados no rumem promovendo menor deposição de gorduras insaturadas (HOEQUETTE e BAUCHART, 1999). Conseqüentemente, ácidos graxos intramusculares são compostos por $50 \%$ de gordura saturada e $50 \%$ de gordura insaturada. Dessa forma, pode-se abordar pontos positivos e negativos em relação à ingestão de carnes. Com o avanço dos estudos nutricionais e tecnológicos alguns conceitos estão sendo reformulados como, por exemplo, a definição dos nutrientes essenciais.

A aterosclerose deixou de ser vista como doença de lipídios para ser estudada como processo dinâmico e progressivo, oriundo da disfunção endotelial e de inflamação. O estudo da patogênese desse processo, entendendo os mecanismos celulares e moleculares, é fundamental para a elaboração de intervenções preventivas (BAHIA et al., 2004). Para BAHIA et al. (2004), as gorduras não são as únicas vilãs em relação ao desenvolvimento de problemas ateroscleróticos e sim a interação de fatores ambientais, genéticos e nutricionais.

Quando se mencionam carnes e derivados cárneos, o termo zoonutriente é ideal para descrevê-los. Trata-se de terminologia específica para produtos de origem animal consumidos por outros animais e que permitem benefícios de ordem nutricional, além do clássico fornecimento de energia para a metabolização (WARD, 2003). A Quadro 4 ilustra as diferentes classes de zoonutrientes, os quais não incluem vitaminas e minerais por não serem sintetizados pelos organismos em questão. 


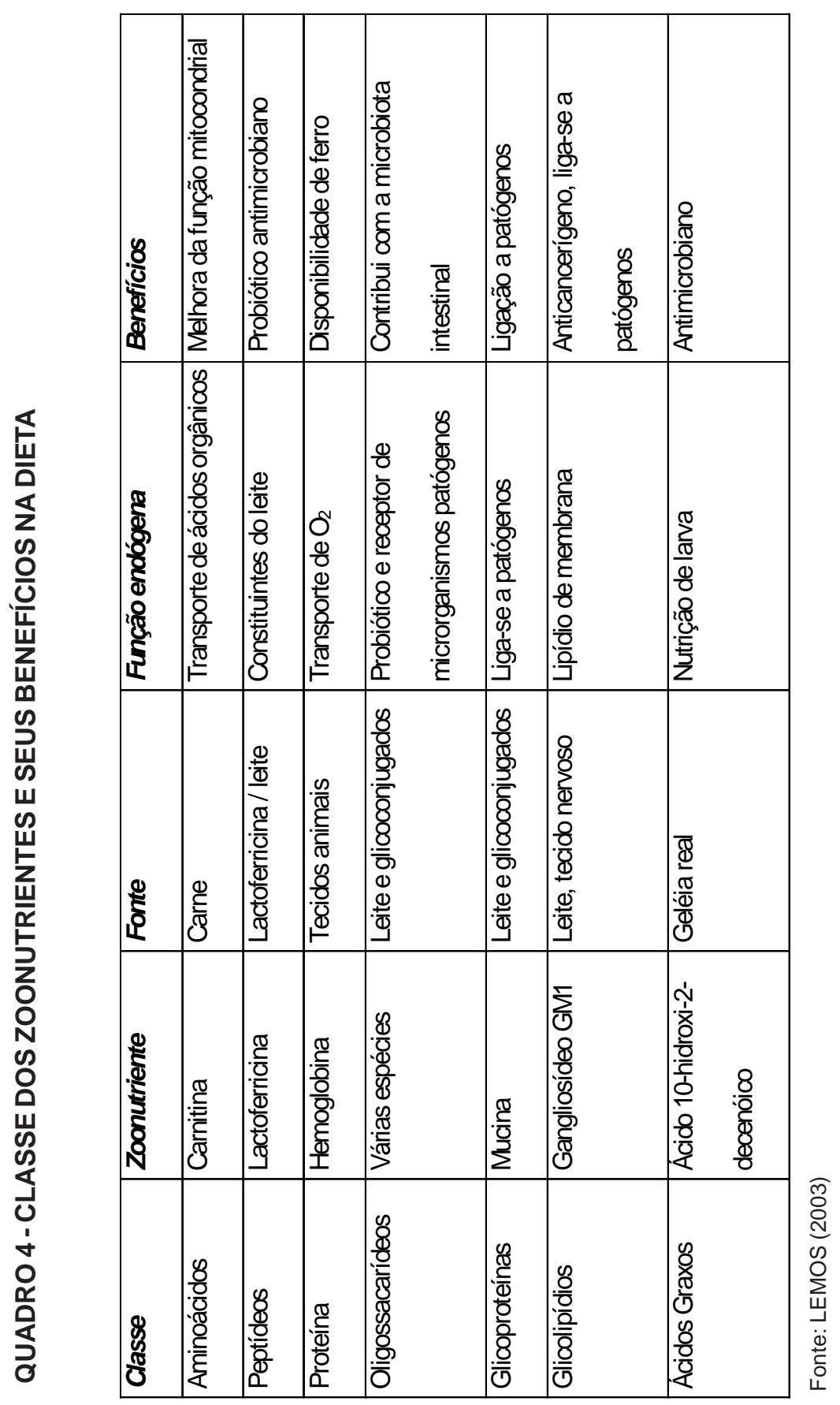


Além dos vinte aminoácidos comumente mencionados, a carne contém taurina que encontra grande aplicação em produtos como bebidas energéticas e suplementos alimentares (LOMBARDINI e SCHAFFER, 2002). Outro componente interessante é a creatina, molécula derivada de aminoácido que tem como função fornecer ATP adicional para a musculatura. Apesar de seu mecanismo ser conhecido, não está bem definido como sua inserção na alimentação pode elevar sua concentração na musculatura (VOLEK et al., 1997).

Resumindo, os produtos cárneos e seus derivados representam benefícios para o organismo humano com ressalva para a ingestão excessiva de gorduras saturadas e colesterol (associados aos diferentes fatores de risco para a saúde). Os demais constituintes apresentam efeitos benéficos e conseqüentemente podem ser relacionados com a funcionalidade desses produtos em diversos processos metabólicos.

\section{COMPONENTES DO SANGUE BOVINO}

O sangue bovino compõe-se de cerca de $81 \%$ de água, $17 \%$ de proteínas, $0,2 \%$ de gordura, $0,07 \%$ de carboidratos e $0,6 \%$ de sais minerais (ALENCAR, 1983). Sua composição é similar à da carne, com exceção para o ferro que tem concentração dez vezes maior (WISMERPEDERSEN, 1979; ALENCAR, 1983). Algumas proteínas encontradas no soro de leite são de origem sanguínea, como a albumina do soro e imunoglobulinas (WALZEM, DILLARD e GERMAN, 2002). Segundo HOWELL e LAWRIE (1983) e HALLIDAY (1975), as proteínas estão distribuídas em albuminas, imunoglobulinas, $\alpha$ - e $\beta$-globulinas e fibrinogênio.

As proteínas do sangue têm sido associadas com diferentes propriedades funcionais (LEE, LOVER e JOHSON, 1993) e como suplemento alimentar (DEL RIO DE REYES et al., 1980), atuando na suplementação de ferro devido sua elevada biodisponibilidade (VITERI et al., 1995).

\section{CONCLUSÃO}

Apesar de bastante estudados, os componentes ativos de origem animal ainda não são integralmente compreendidos. Como fonte de alimentos e ingredientes alimentares, esses componentes podem ser empregados para solucionar ou minimizar deficiências nutricionais. No entanto, a 
necessidade e a importância do estudo de compostos bioativos têm sido associadas à demanda cada vez maior desses tipos de ingredientes pelo mercado consumidor.

\begin{abstract}
ACTIVE COMPONENTS FROM ANIMAL FOOD SOURCES

The present review has as objective to discuss the physiological activities related to components of animal source. Milk and its components, meat products, bovine blood components and the regulamentation of functional or nutraceutical foods were investigated. It was concluded that although the active compounds of animal source are well studied they are still not integrally understood. As source of foods and alimentary ingredients, those components can be used to solve or to minimize nutritional deficiencies. However, the need and importance of the study of bioactive compounds have been associated to the demand every time larger for those types of ingredients in the consuming market.
\end{abstract}

KEY-WORDS: ANIMAL ORIGIN; NUTRACEUTICALS; PHYSIOLOGICAL PROPRERTIES.

\title{
REFERÊNCIAS
}

1 ADA. American Dietetic Association. Position of the American Dietetic Association: functional foods. Journal of the American Dietetic Association, Philadelphia, v. 99 , p. $1278-1285,1999$.

2 AIMUTIS, W.R. Bioactive properties of milk proteins with particular focus on anticariogenesis. The Journal of Nutrition, Bethesda, v. 134, p. 989-995, 2004.

3 AIMUTIS, W.R. Safety aspects related to milk-derived bioactives. Bulletin of the International Dairy Federation, Raanana, v. 375, p. 130-135, 2002.

4 ALENCAR, F.A. Estudos da recuperação das proteínas do plasma bovino por complexação com fosfatos e a sua utilização em produtos cárneos. Campinas, 1983. Tese (Doutorado em Tecnologia de Alimentos), Faculdade de Engenharia de Alimentos, Universidade Estadual de Campinas.

5 ALI, S.; CLARK, A.J. Characterization of the gene encoding ovine $\beta$-lactoglobulin. Journal of Molecular Biology, Oxford, v. 199, p. 415-426, 1988.

6 AL-MASHIKHI, S.A.; NAKAI, S. Isolation of bovine immunoglobulins and lactoferrin from whey proteins by gel filtration techniques. Journal of Dairy Science, Athens, v. 70, p. 2486-2492, 1987.

7 ANVISA. Agência Nacional de Vigilância Sanitária. 2004a. Resolução no 19 de 30 de abril de 1999. Disponível em: http://e-legis.bvs.br/leisref/public/ showAct.php?id=197\&word. Acesso em: 20 mar. 2004a.

8 ANVISA. Agência Nacional de Vigilância Sanitária. 2004b. Diretrizes Básicas para Análise e Comprovação de Propriedades Funcionais e ou de Saúde Alegadas 
em Rotulagem de Alimentos. Informe Técnico ANVISA/MS, n. 9 de 21 de maio de 2004b.

9 ANTUNES, A.J. Funcionalidade de proteínas do soro de leite bovino. Barueri: Manole, 2003. 135 p.

10 ARAI, S. Studies on functional foods in Japan: state of the art. Bioscience, Biotechnology and Biochemistry, Tóquio, v. 60, p. 9-15, 1996.

11 ARAÚJO, A.N.; GIUGLIANO, L.G. Lactoferrin and free secretory component of human milk inhibit the adhesion of enteropathogenic Escherichia coli to HeLa cells. BMC Microbiology, London, v. 1, p. 25-30, 2001.

12 BAHIA, L.; AGUIAR, L.G.K.; VILLELA, N.R.; BOTTINO, D.; BOUSKELA, E. Endotélio e aterosclerose. Revista da SOCERJ, Rio de Janeiro, v. 17, n. 1, p. 26-32, 2004.

13 BAL-DIT-SOLLIER, C.; DROUET, L.; PIGNAUD, G.; CHEVALLIER, C.; CAEN, J.; FIAT, A.M.; IZQUIERDO, C.; JOLLES, P. Effect of $\kappa$-casein split peptides on platelet aggregation and on thrombus formation in the guinea-pig. Thrombosis Research, New York, v. 81, p. 427-437, 1996.

14 BESSI, R. Estudo da absorção de anticorpos do colostro em bezerros recém-nascidos. Piracicaba, 2001. 58 p. Tese (Doutorado em Nutrição Animal), Escola Superior de Agricultura "Luiz de Queiroz", Universidade de São Paulo.

15 BLOMSTRAND, E.; NEWSHOLME, E.A. Effect of branched-chain amino acid supplementation on the exercise-induced change in aromatic amino acid concentration in human muscle. Acta Phisiologica Scandinavica, Odense, v. 146, p. 293-298, 1992.

16 CARROL, K.K.; KUROWSKA, E.M. Soy consumption and cholesterol reduction: review of animal and human studies. The Journal of Nutrition, Bethesda, v. 125, p. 594-597, 1995.

17 CARROL, K.K. Review of clinical studies on cholesterol lowering response of soy protein. Journal of the American Dietetic Association, Philadelphia, v. 91, p. 820-827, 1991.

18 CHIZZOLINI, R.; NOVELLI, E.; ZANARDI, E. Oxidation in traditional Mediterranean meat products. Meat Science, Savoy, v. 49, n. 1, p. 87-99, 1998.

19 CLYDESDALE, F.M. A proposal for the establishment of scientific criteria for health claims for functional foods. Nutrition Reviews, Boston, v. 55, n. 12, p.413-422, 1997.

20 COBAYASHI, F. Cálcio: seu papel na nutrição e saúde. Compacta Nutrição, São Paulo, v. 5, n. 2, p. 1-14, 2004.

21 COELHO, R.G. Interações nutricionais. Revista de Metabolismo e Nutrição, Porto Alegre, v. 2, n. 3, p.106-117, 1995.

22 CRAGG, G.M.; NEWMAN, D.J.; SNADER, K.M. Natural products in drug discovery and development. Journal of Natural Products, Columbus, v. 60, p. 52-60, 1997. 
23 CRAVIOTTO, A.; TELLO, A.; VILLAFAN, H.; RUIZ, J.; VEDOVO, S.; NEESER, J.R. Inhibition of localized adhesion of enteropathogenic Escherichia coli to Hep-2 cells by immunoglobulin and oligosaccharide fractions of human colostrum and breast milk. The Journal of Infection Disease, Boston, v. 163, p. 1247-1255, 1991.

24 CRUZ, C.R.; GIL, L.; CANO, F.; CACERES, P.; PAREJA, G. Breast milk anti Escherichia coli heat labile toxins: IgA antibodies protect against toxin induced infantile diarrhoea. Acta Paediatrica Scandinavica, Stockholm, v. 77, p. 658662, 1988.

25 CUNNINGHAM, J.G. Textbook of veterinary physiology. Philadelphia: W.B. Saunders, 1999. 528 p.

26 DEL RIO DE REYES, M.T.E.; CONSTANTINIDES, S.M.; SGARBIERI, V.C.; EL-DASH, A.A. Chicken blood plasma proteins: physicochemical, nutritional and functional properties. Journal of Food Science, Chicago, v. 46, p. 1782-1784, 1980.

27 EIGEL, W.N.; BUTLER, J.E.; EMSTROM, C.A.; FARRELL, H.M.; HARWALKER, V.R.; JENNESS, R.; WHITNEY, R.M. Nomenclature of proteins of cow's milk: fifth revision. Journal of Dairy Science, Athens, v. 67, p. 1599-1631, 1984.

28 FARREL, H.M.; WICKHAM, E.D.; DOWER, H.J.; PIOTROWSKI, E.G.; HOAGLAND, P.D.; COOKE, P.H.; GROVES, M.L. Characterization of the particles of purified kappa-casein: trypsin as a probe of surface-accessible residues. Protein Chemistry, v. 18, p. 637-645, 1999.

29 FERNICOLA, N.A.G.G. Os alimentos de origem animal e vegetal e a qualidade do ambiente. In: CIÊNCIA dos alimentos: avanços e perspectivas. Campinas: UNICAMP, 2001. p. 139-141.

30 GEAY, Y.; BAUCHART, D.; HOCQUETTE, J.F.; CULIOLI, J. Effects of nutritional factos on biochemical, structural and metabolic characteristics of muscle in ruminats, consequences on dietetic value and sensorial qualities of meat. Reproduction, Nutrition, Development, Les Ulis, v. 41, p. 1-26, 2001.

31 GIBSON, G.R. Dietary modulation of the human gut microflora using prebiotics. British Journal of Nutrition, London, v. 80, p. 209-212, 1998.

32 GIUGLIANO, L.G.; RIBEIRO, STG.; VAINSTEIN, M.H.; ULHOA, C.J. Free secretory component and lactoferrin of human milk inhibti the adhesion of enteropathogenic Escherichia coli. Journal of Medical Microbiology, Edinburgh, v. 42, p. 3-9, 1995.

33 GOLDMAN, A.S. Modulation of the gastrointestinal tract of infants by human milk. Interfaces and interactions. An evolutionary perspective. The Journal of Nutrition, Bethesda, v. 130, p. 426-431, 2000.

34 GOODMAN, R.E.; SCHANBACHER, F.L. Bovine lactoferrin mRNA: sequence, analysis, and expression in the mammary gland. Biochemical and Biophysical Research Communications, München, v. 180, p. 75-84, 1991.

35 GRUDTNER, V.S.; WEINGRILL, P.; FERNANDES, A.L. Aspectos da absorção no metabolismo do cálcio e vitamina D. Revista Brasileira de Reumatologia, São 
Paulo, v. 37, n. 3, p. 143-151, 1997.

36 GUEGUEM, L.; POINTILLART, A. The bioavailability of dietary calcium. Journal of the American College of Nutrition, Clearwater, v. 19, n. 2, p. 119-136, 2000.

37 HALLIDAY, D.A. Blood: a source of proteins. Process Biochemistry, New York, v. 10, p. 11-12, 1975.

38 HASLER, C.M. Functional foods: their role in disease prevention and health promotion. Food Technology, Chicago, v. 52, n. 11, p. 63-68, 1998.

39 HENRY, C. M. Nutraceuticals: food or trend? Chemical Engineering News, Columbus, v. 21, p. 42-47, 1999.

40 HERNANDEZ, E.R.S.; GUZMAN, I.V. Revisión: alimentos e ingredientes funcionales derivados de la leche. Archivos Latinoamericanos de Nutrición, Caracas, v. 53, n. 4, p. 333-347, 2003.

41 HOEQUETTE, J.F.; BAUCHART, D. Intestinal absorption, blood transport and hepatic and muscle metabolism of fatty acids in preruminant and ruminant animals. Reproduction, Nutrition, Development, Les Ulis, v. 39, p.27-48, 1999.

42 HOWELL, N.K.; LAWRIE, R.A. Functional aspects of blood plasma proteins. I. Separation and characterization. Food Technology, Chicago, v. 18, p. 747-762, 1983.

43 IFICF. International Food Information Council Foundation. Backgrounder: functional foods. In: FOOD Insight Media Guide. Washington, 1998.

44 IMNAS. Committee on Opportunities in the Nutrition and Food Services. Food and Nutrition Board, Institute of Medicine. In: THOMAS, P.R.; EARL R. (eds.) Opportunities in the Nutrition and Food Services: research challengers and the next generation of investigations. Washington: National Academy Press, 1994.

45 JELEN, P.; LUTZ, S. Functional foods, biochemical and processing aspects. Lancaster: Technomic Publishing, 1998. p. 357-380.

46 KOURY, J.C.; DONANGELO, C.M. Zinc, oxidative stress and physical activity. Revista de Nutrição, Campinas, v. 16, n. 4, p. 433-441, 2003.

47 KRAUSE, M.V.; MAHAN, L.K. Alimentos, nutrição e dietoterapia. 7. ed. São Paulo: Editora Roca, 1991. 978 p.

48 LEE, C.C.; LOVE, J.A.; JOHNSON, L.A. Sensory and physical properties of cakes with bovine plasma products substituted for egg. Cereal Chemistry, St. Paul, v. 70, p. 18-21, 1993.

49 LEMOS, A.L.C. Zoonutrientes: carne e produtos cárneos, uma nova abordagem nutricional. CTC Tecnocarnes, Campinas, v. 13, n. 3, p. 5-8, 2003.

50 LOMBARDINI, J.B.; SCHAFFER, S.W. Special issue: taurine, discovered 185 years ago and still intrigues the scientific community. Aminoacid, v. 23, p. 343, 2002.

51 MEISEL, H.; BOCKELMANN, W. Bioactive peptides encrypted in milk proteins: 
proteolytic activation and thropho-functional properties. Antonie Van Leeuwenhoek, Newcastle, v. 76, p. 207-215, 1999.

52 MORRISSEY, P.J. Lipid stability in meat and meat products. Meat Science, Savoy, v. 49, n. 1, p. 73-86, 1998.

53 NAGAOKA, S.; KANAMARU, Y.; KUZUYA, Y.; KOJIMA, T.; KUWATA, T. Comparative studies on the serum cholesterol lowering action of whey protein and soybean protein in rats. Bioscience, Biotechnology and Biochemistry, Tóquio, v. 56, p. 1484-1485, 1992.

54 OHR, L.M. A growing arsenal against cancer. Food Technology, Chicago, v. 56, n. 7, p. 67-71, 2002.

55 PENNINGTON, J.A.T. Food composition databases for bioactive food components. Journal of Food Composition and Analysis, Roma, v. 15, p. 419-434, 2002.

56 PEREZ, M.D.; CALVO, M. Interaction of beta-lactoglobulin with retinol and fatty acids and its role as a possible biological function for this protein: a review. Journal of Dairy Science, Athens, v. 78, p. 978-988, 1995.

57 PETROVICK, P.R.; MARQUES, L.C.; PAULA, I.C. de. New rules for phytopharmaceutical drug registration in Brazil. Journal of Ethonopharmacology, Leiden, v. 66, n. 1, p. 51-55, 1999.

58 POTTER, S.M.; BAKHIT, R.M.; ESSEX-SOLIE, D.L.; WLINGARTNER, K.E.; CHAPMAN, K.M.; NELSON, R.A.; PRABHUDESAI, M.; SAVAGE, W.D.; NELSON, A.I.; WINTER, L.W.; ERDMAN, J.W. Depression of plasma cholesterol in men by consumption of baked products containing soy protein. American Journal of Clinical Nutrition, Bethesda, v. 58, p. 501-506, 1993.

59 PRATES, J.A.M.; MATEUS, C.M.R.P. Physiologically active components from animal food sources. Revista Portuguesa de Ciência Veterinária, Lisboa, v. 97, n. 541, p. 3-12, 2002.

60 SAID, H.M.; ONG, D.E.; SHINGLETON, J.L. Intestinal uptake of retinol: enhancement by bovine milk beta-lactoglobulin. American Journal of Clinical Nutrition, Bethesda, v. 49, p. 690-694, 1989.

61 SANDERS, M.E. Overview of functional foods: emphasis on probiotic bacteria. International of Dairy Journal, v. 8, n. 5/6, p. 341-347, 1998.

62 SAUTIER, K.; DIENG, K.; FLAMENT, C.; DOUCET, C.; SUQUET, J.P.; LEMONNIER, D. Effects of whey protein, casein, soya-bean and sunflower protein on the serum, tissue and faecal steroids in rats. British Journal of Nutrition, London, v. 49, p. 313-319, 1983.

63 SCHENA, F.; GUERRINI, F.; TREGNAGHI, P.; KAYSER, B. Branched-chain amino acid supplementation during trekking at high altitude: the effects on loss of body mass, body composition, and muscle power. European Journal of Applied Physiology, Berlin, v. 65, p. 394-398, 1992.

64 SEYFERT, H.M.; TUCKORICZ, A.; INTERTHAL, H.; KOCZAN, D.; HOBOM, G. Structure of the bovine lactoferrin-encoding gene and its promoter. Gene, Napoli, 
v. 143, p. $265-269,1994$.

65 SHAH, N.P. Effects of milk-derived bioactivities: an overview. British Journal of Nutrition, London, v. 84, p. 3-10, 2000.

66 STEIJNS, J.M. Milk ingredients as nutraceuticals. International Journal of Dairy Technology, Oxon, v. 54, p. 81-88, 2001.

67 TAWA, N.E.; GOLDBERG, A.L. Suppression of muscle protein turnover and amino acid degradation by dietary protein deficiency. American Journal of Physiology, Bethesda, v. 263, p. 317-325, 1992.

68 VAGHELA, M.; KILARA, A. Lipid composition of whey protein concentrates manufactured commercially and in the laboratory. Journal of Dairy Science, Athens, v. 79, p. 1172-1183, 1996.

69 VESPER, H.; SCHMELZ, E.M.; NIKOLOVA-KARAKASHIAN, M.N.; DILLEHAY, D.L.; LYNCH, D.V.; MERRILL, A.H. Sphingolipids in food and the emerging importance of sphingolipids to nutrition. The Journal of Nutrition, Bethesda, v. 129, p. 12391250, 1999.

70 VITERI, E.; ALVAREZ, E.; BATRES, R.; TORUN, B.; PINEDA, O.; MEJIA, L.A.; SYLVI, J. Fortification of sugar with iron sodium ethylenediaminotetracetate (FeNaEDTA) improves iron status in semirural Guatemala populations. American Journal of Clinical Nutrition, Bethesda, v. 61, p. 1152-1163, 1995.

71 VOLEK, J.S.; KRAEMER, W.J.; BUSH, J.A.; BOETES, M.; INCLEDON, T.; CLARKC, K.L.; LYNCH, J.M. Creatinine supplementation enhances muscular performance during high intensity resistence exercice. Journal of the American Dietetic Association, Philadelphia, v. 97, p. 765-770, 1997.

72 WALZEM, R.L.; DILLARD, C.J.; GERMAN, J.B. Whey components: millennia of evolution create functionalities for mammalian nutrition: what we know and what we may be overlooking. Critical Reviews in Food Science and Nutrition, Philadelphia, v. 42, n. 4, p. 353-375, 2002.

73 WARD, R.E.; GERMAN, J.B. Zoonutrients and heath. Food Technology, Chicago, v. 57, n. 3, p. 30-36, 2003.

74 WEISBURGER, J.H. Eat to live, not live to eat. Nutrition Notes, New York, v. 16, p. 767-773, 2000.

75 WISMER-PEDERSEN, J. Utilization of animal blood meat products. Food Technology, Chicago, v. 33, p. 76-80, 1979.

76 YVON, M.; BEUCHER, S.; GUILLOTEAU, P.; LE HUEROU-LURON, I.; CORRING, T. Effects of caseinomacropeptide (CMP) on digestion regulation. Reproduction, Nutrition, Development, Les Ulis, v. 34, p. 527-537, 1994.

77 ZEMEL, M.; MILLER, S.L. Dietary calcium and dairy modulation of adiposity and obesity risk. Nutrition Reviews, Washington, v. 62, n. 4, p. 125-131, 2004. 